\title{
IODINE IN FISH AND CRABS FROM SRI LANKAN WATERS
}

\author{
S.P. DERANIYAGALA*, W.V.S.M. PERERA and W.S. FERNANDO \\ Department of Chemistry, University of Sri Jaycwardenepura, Nugegoda.
}

(Received: 10 February 2000 ;accepted: 03 November 2000)

\begin{abstract}
The iodine content of twenty seven species of marine/fiesls water fish and crabs collected from different areas of Sri Lanka on different days was determined. The iodine content was determined using the Sandell and Kolthoff reaction. Marine crah flesh (Neptumus pelagicus, $62.3 \pm 2.8 \mu \mathrm{g} / 100 \mathrm{~g}$; Neptumus sanguinolentus, $95.8 \pm 4.9 \mu \mathrm{g} / 100 \mathrm{~g}$ ) are rich sources of judine, compared to lacoon crab (Scyll.a. serrata, $29.4 \pm 1.9 \mu \mathrm{g} / 100 \mathrm{~g})$. Most of the indine in crabs is concentrated in the gills, thus identifying crabs as the sea food richest in iodine. The iodine content of marine fish was found to be significantly higher (three to five times) than that of tresh water tish except in the case of Histophlorous gladius which had a very low jodine level. Large marine pelagics had a siguificantly lower level of iodine than smaJl pelagics. All species under study lost iodine on bojiling. The percentage loss of iodine from crabs was ahout the sane as fiom praws. A comparison of percentage iodine losses from marine/fresl. water fisb and crabs during boiling indicates that the losses fiom lagoon crabs, large marine pelagics and fresh water fish are significantly higher than from marine crabs, small marine pelagics and marine fïsli respectively.
\end{abstract}

Key words: crahs, fiesh water fish, iodine, marine fish

\section{INTRODUCTION}

Iodine is an essential trace element in human nutrition. This element needs to be ingested regularly consistent with the recommended daily allowance. A complex mechanism has evolved to acquire iodine from food and water and to incorporate it into tyrosine of thyroglobulin and eventually to synthesize thyroid hormones.

Sea water fish and other marine foods are frequently regarded as a major natural source of dietary jodine, but little is known about their fresh water counterparts. In spite of the importance of iodine to human health, there are no publications on the iodine content of sea foods consumed in Sri Lanka apart from studies of this group. ${ }^{1,2}$

Recently, we reported ${ }^{1}$ a study on iodine in marine prawns and its fate on boiling. However, more information on iodine in sea foods will undoubtedly be of value to the food industry, medical services (doctors/dieticians) academia and the general public.

\footnotetext{
${ }^{+}$Conresponding author:

Preliminary work on marine crabs (Neptunus pelagicuss) was presented at the annual sessions of the Sri Lanka Association for the Advancement of Science 1996.
} 
The objective of this study was to determine the iodine content of commonly consumed marine/fresh water fish and crabs in the hope of filling a gap in the knowledge of the dietary value of these species.

Twenty seven species including marine fish, fresh water fish and crabs were studied.

\section{METHODS AND MATERIALS}

Sampling of crabs for analysis: All crab species mentioned (Table 1) were collected from vendors early in the morning on Negombo beach. Samples of each species, collected on three different days during the period April to June 1996, were analyzed. Neptunus sanguinolentus, however, was less abundant and analysis has been limited to two days with a smaller number of samples. All specimans used in the analyses were approximately of the same size (Carapace length : Neptunus pelagicus, $11.0 \pm 0.7 \mathrm{~cm} ;$ Neptunus sanguinolentus, $8.5 \pm 0.9 \mathrm{~cm}$ and Scylla serrata, $9.5 \pm 0.7 \mathrm{~cm}$ ).

Sampling of fish for analysis: Marine fish samples (Table 2) were collected over a period of one year (October 1994 - November 1995) on three different days from Nugegoda fish market. Samples of flesh of the small pelagics were taken from the centre whereas with large pelagics, they were taken from the dorsal part of the trunk. Four marine species (Thunnus albacares, Katsuwonus pelamis, Amblygaster sirm and Sardinella melanura) were also sampled from the Kandy fish market. This was done to ascertain whether significant losses of iodide had taken place in fish that were less fresh than what was available at Nugegoda.

Fresh water fish were collected on two different days from markets of Digana, Hanwella, Kurunegala or Horana during the months of December 1996 to January, 1997.

Ashing of samples, determination of iodide (using the Sandell and Kolthoff reaction) and statistical analysis of results were similar to those described by us earlier. ${ }^{1}$

\section{RESULTS}

Table 1 gives the iodine levels of three species of crabs collected on different days from Negombo. The mean iodine level of raw thoracic muscles varied from 29 to $96 \mu \mathrm{g} / 100 \mathrm{~g}$ wet weight and was highest for Neptunus sanguinolentus. The presence of extremely high levels of iodine in gills has been observed in marine crabs. It is also evident from Table 1 that $35-55 \%$ of iodine in raw flesh is lost on boiling. The percentage iodide loss in marine crabs $(33.5 \pm 3.7)$ is significantly less than in lagoon crabs $(49.9 \pm 4.7)$. Crab shells are also found to contain considerable quantities of iodine similar to prawn shells. 


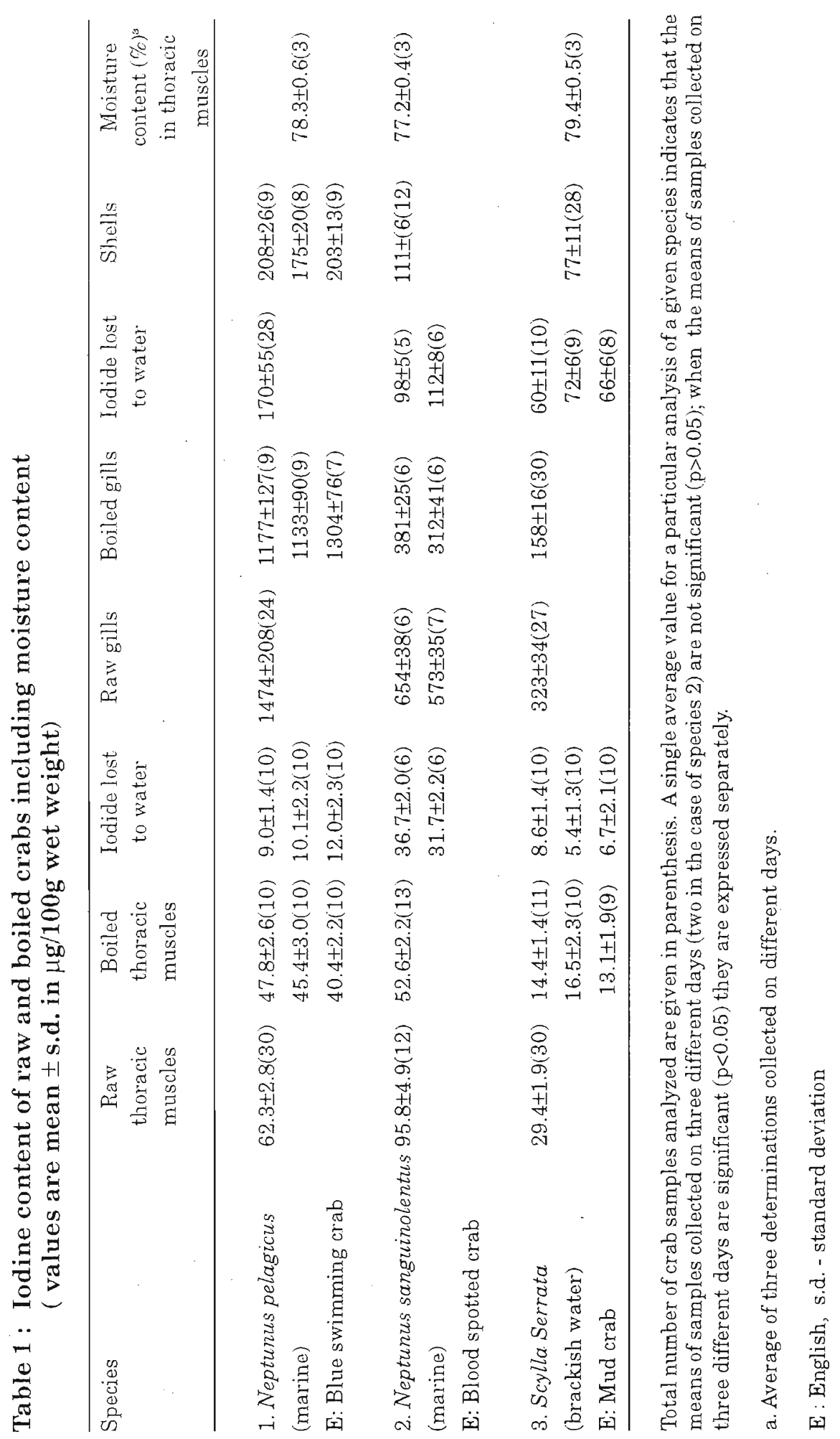




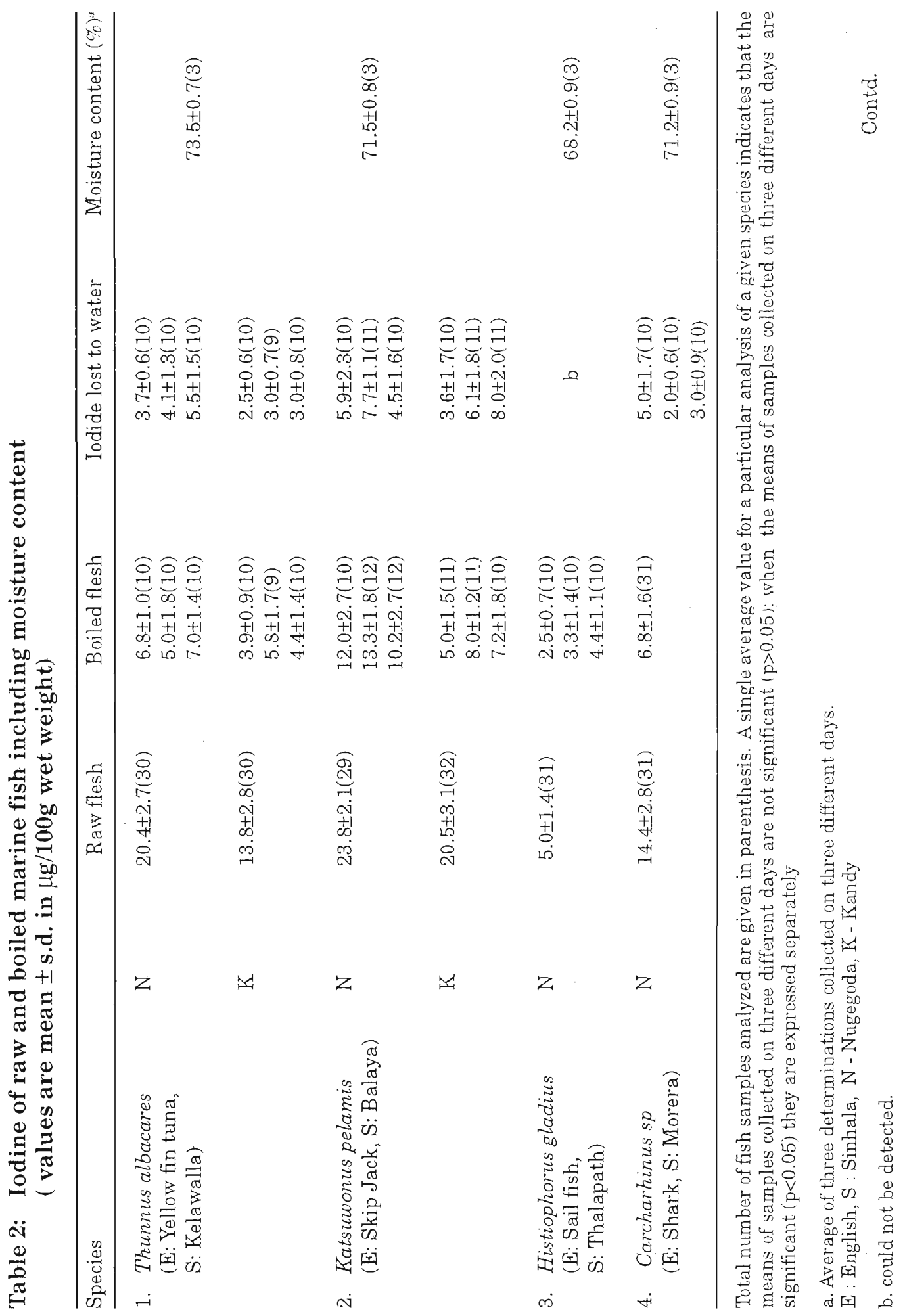




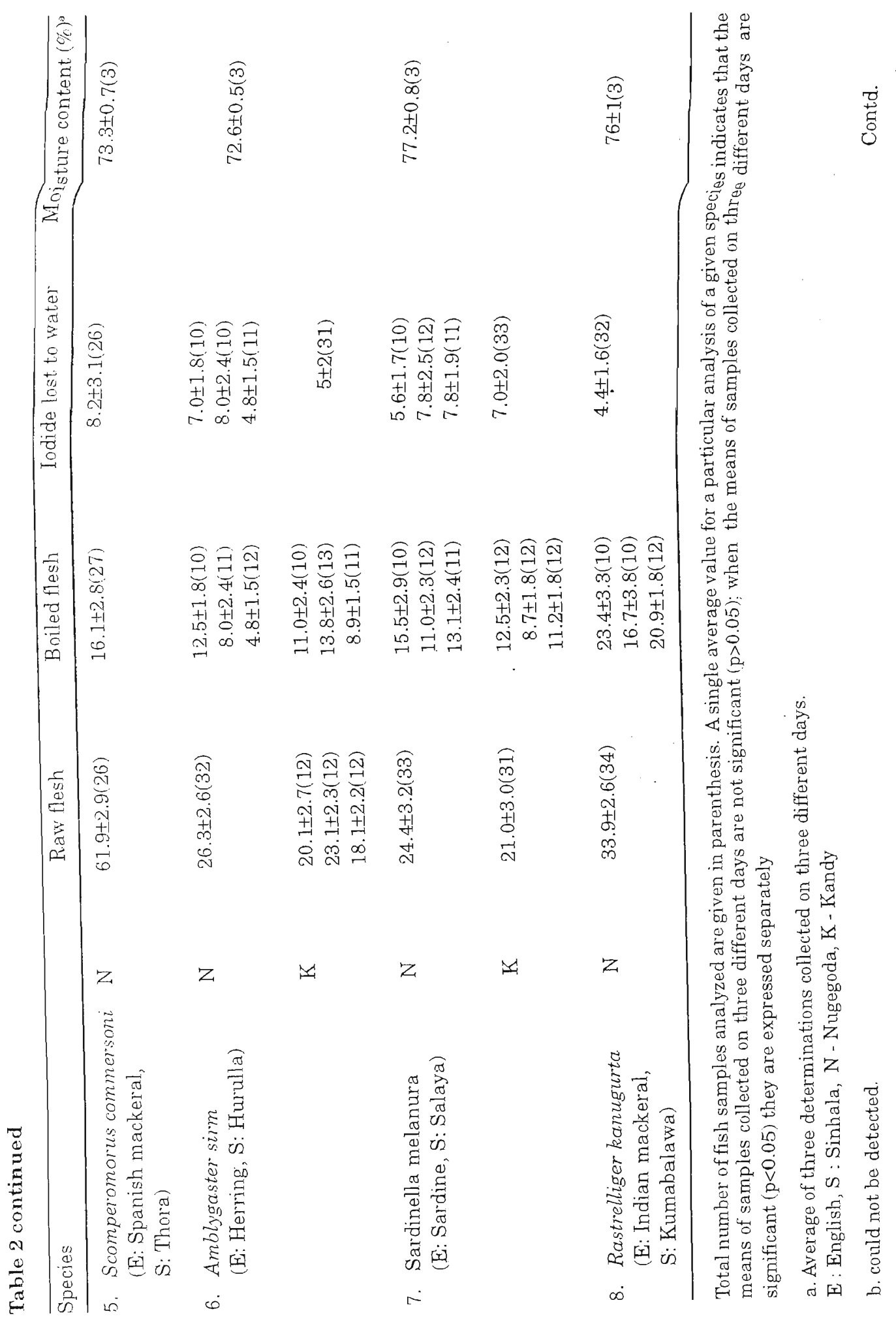




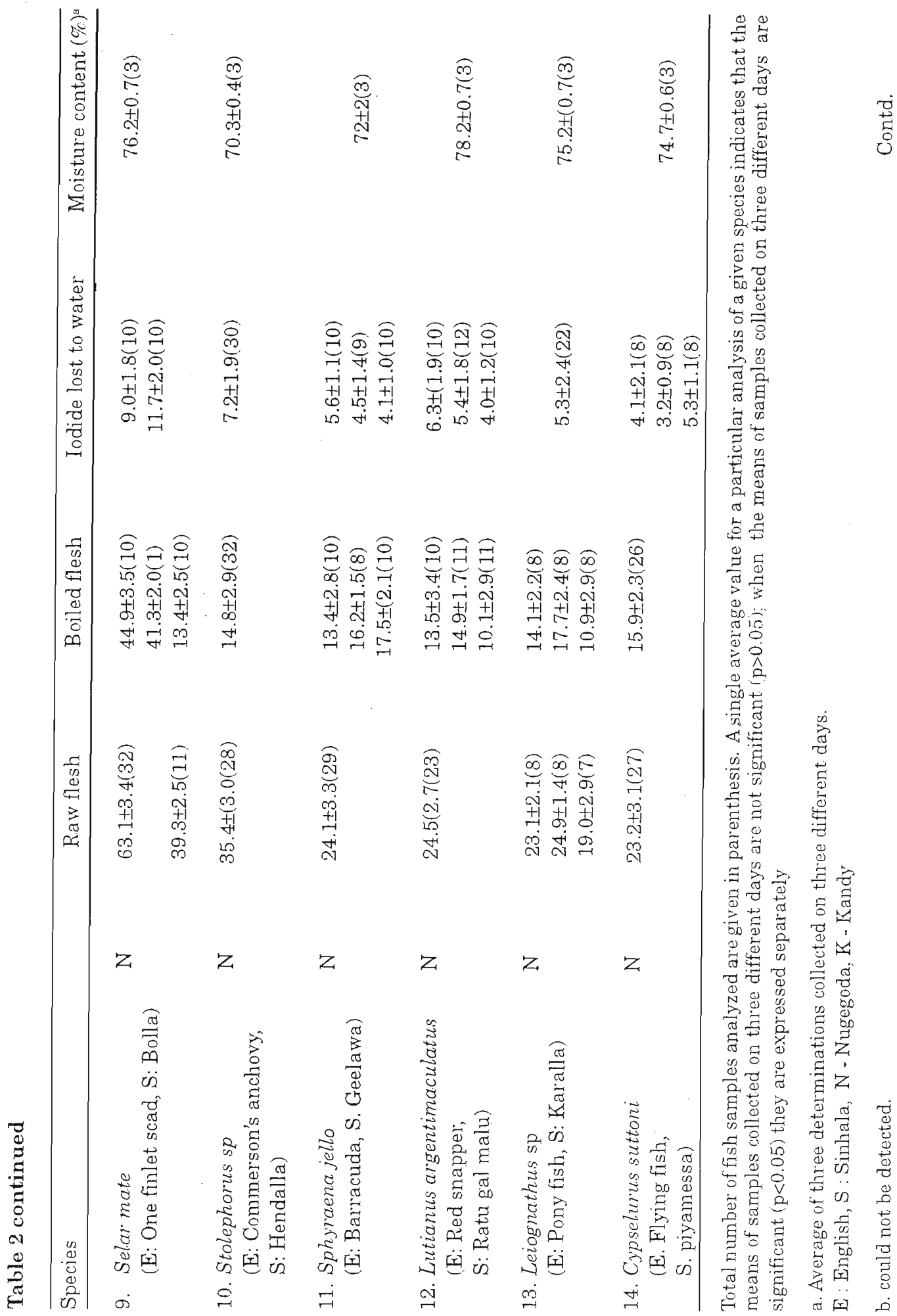




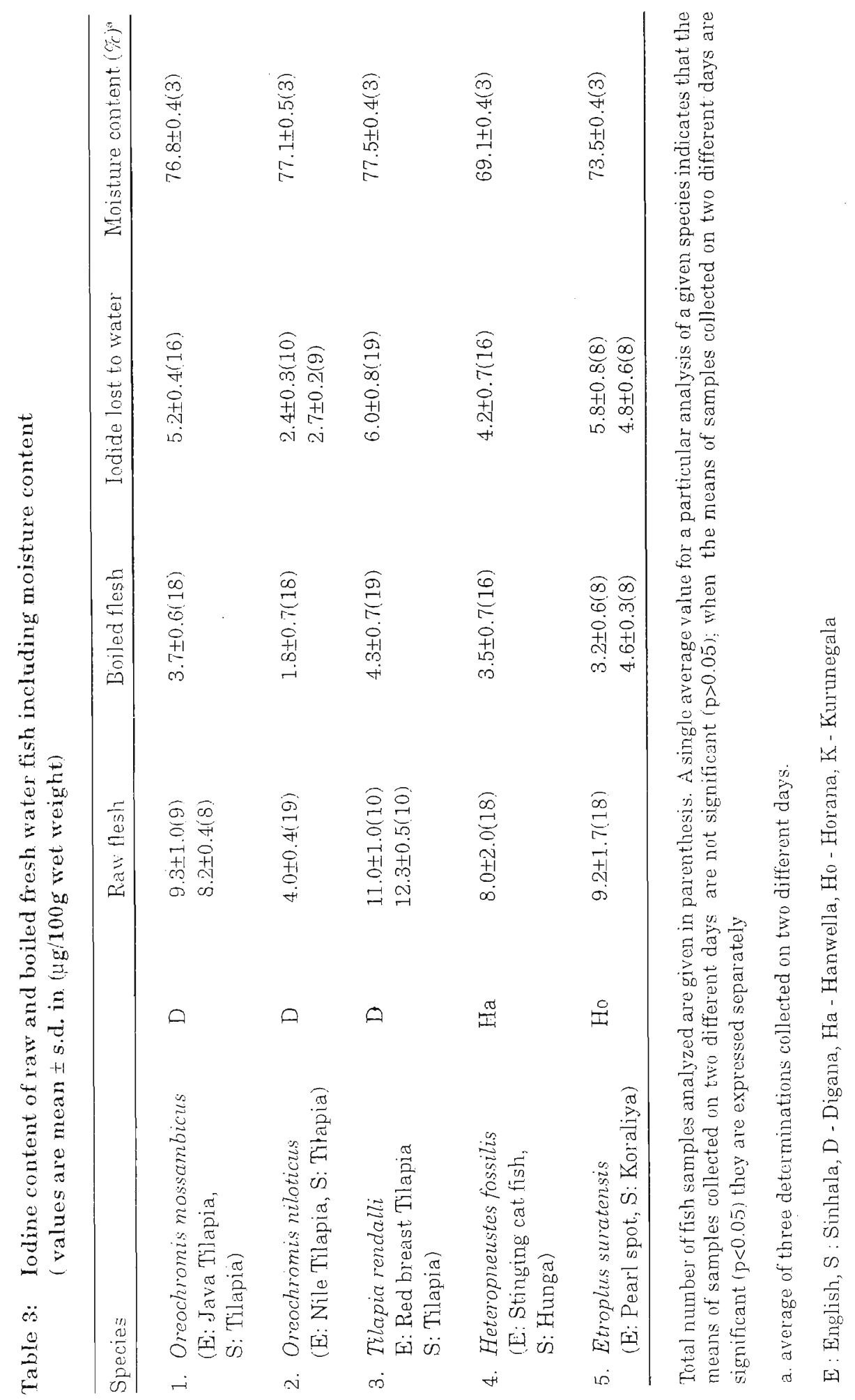




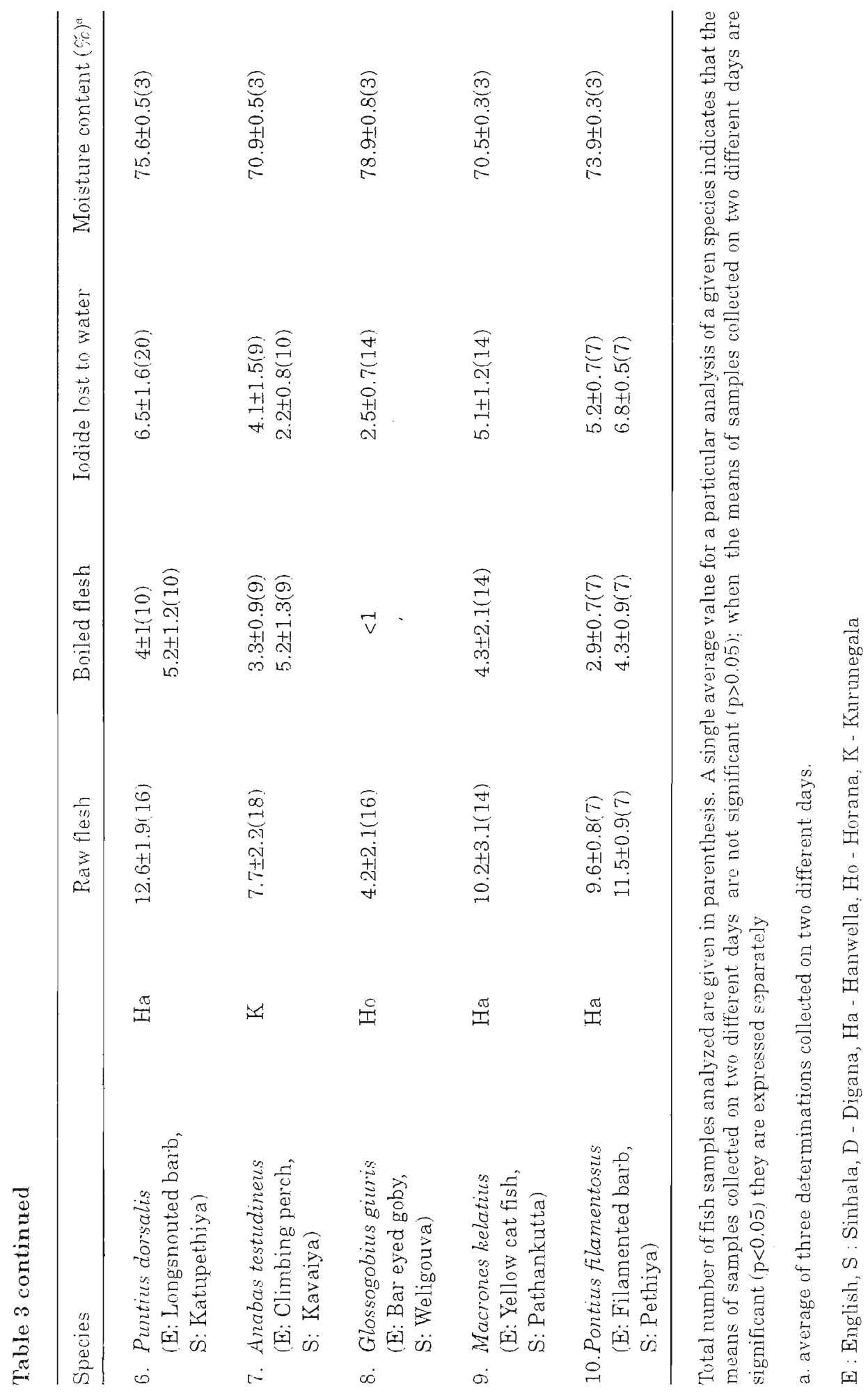


Table 2 and 3 give the iodine contents of raw flesh (fillet) in marine fish and fresh water fish respectively. The iodine ranges from a low of $5 \mu \mathrm{g} / 100 \mathrm{~g}$ in Histiophorus gladius to a high of $63 \mu \mathrm{g} / 100 \mathrm{~g}$ in Selar mate for marine fish. In the case of fresh water fish the levels were lower and significantly different from marine fish and fell in the range $4.0-12.6 \mu \mathrm{g} / 100 \mathrm{~g}$ wet weight. The relative percentage loss of iodine in marine large pelagics $(55.7 \pm 16.3)$ is significantly higher than that from small pelagics $(42.5 \pm 12.5)$. The loss of iodine from fresh

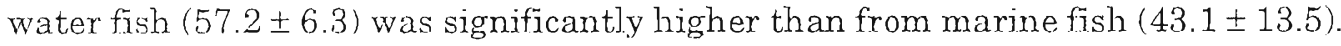

\section{DISCUSSION}

The data in column 1 of Table 1 reveal that marine crabs are significantly higher in jodine than lagoon crabs. Furthermore, marine crab flesh is richer in iodine than prawn flesh $(17-20 \mu \mathrm{g} / 100 \mathrm{~g}){ }^{1}{ }^{1}$ The presence of extremely high levels of iodine in gills could identify crabs as the sea food richest in iodine hitherto known. Although gills are a rich source of jodine, it is not nutritionally important, as gills are not consumed. The fate of iodine during boiling has also been determined. The relative loss is in the same range as that observed for prawns. Unlike in prawns, crabs are usually cooked with shell intact. The fact that crab shells contain high levels of iodine, suggests that migration of iodine from shell to the flesh could occur during boiling, although more slowly, as observed for prawns. Under such situation, boiled thoracic muscies may show elevated iodide levels to those reported in column 2 of Table 1.

The low iodine level in Scylla serrata may be attributed to the low salinity of the brackish water in the Negombo lagoon. The low salinity may be due to the high rain fall experienced during the period April to June 1996. An examination of seasonal variation of salinity in the Negombo lagoon during the period $1985-1987$ and monthly rainfall pattern observed in the catchment area of Negombo during this period:" strongly supports the origin of the low iodine level in Scylla serrata.

Ln general, iodine content in fillet of sea water fish is three to five times high than of fresh water fish. It has been shown that fish absorb iodine both from the water and the food they eat, ${ }^{4}$ High iodine concentration in marine fish species may be the result of higher iodine concentration not only in salt water than in fresh water but also in the food supply of the marine fish. Small pelagics showed high level of indine $(23-63 \mu \mathrm{g} / 100 \mathrm{~g})$ than large pelagics $(5-23 \mu \mathrm{g} / 100 \mathrm{~g})$. It should be noted, however, that the spanish mackeral categorized under large pelagics does not fall in the latter range. Large pelagics in the study were the yellow fin tuna, skip jack, spanish mackeral, sail fish and shark.

Although levels of iodine in marine fish reported, compared well with those reported values for marine fish in other countries, a recent study of iodine content in fillet of different species of fish from Norway and India ${ }^{6}$ reported values 
ranging from 50 to $560 \mu \mathrm{g} / 100 \mathrm{~g}$ and 144 to $328 \mu \mathrm{g} / 100 \mathrm{~g}$ respectively. This may be due to the fact that iodine composition in marine fish is an uncontrollable variable due to geographical location of catch, season of the year, sex and feeding habits of. the species. An important observation in this study is that the mean iodine levels of marine fish fillet of a particular species collected on three different days are largely not significant $(p>0.05)$. Crabs and fresh water fish also show similar patterns.

Working on the presumption that average daily per capita fish consumption is $40 \mathrm{~g}$ per day ${ }^{\bar{\top}}$, this study reveals that a single fish meal does not provide the daily requirement $(150 \mu \mathrm{g})$ and has to be supplemented by other iodine rich sources.

It is evident from Table 2 that jodine in fish collected from Kandy were low and significantly different to those from Nugegoda. The fact that we have observed more deterioration in fish collected from Kandy leads to the conclusion that storage plays an important role in preserving the nutritional qualities (jodine in this case) of fish.

Preliminary investigations in our laboratory show that iodine is concentrated largely in the skin in the case of large marine pelagics. Further work is underway to establish in detail the distribution of iodide in fish.

\section{Acknowledgement}

This study was funded by Unjversity of Sri Jayewardenepura (ASP/4/RE/93/07) and NAFESA (RG/C/95/02). The authors also thank Prof. J. Jinadasa, Dr. Ajantha Alwis, Mr. P. Dias and Prof. A. Bamunuarachchi for help during the various stages of this project.

\section{References}

1. Deraniyagala S.P. \& Perera W.V.S.M. (1999). Iodine in marine prawns and its fate on boiling. Journal of the National Science Foundetion of Sri Lanka $27(3): 1.97-202$.

2. Deraniyagala S.P., Perera W.V.S.M., Fernando W.S. \& Bamunusinghe W.S.P. (1999). Iodine in pulses and cereals. Vidyodaya onurmal of Science 8: 173 -180 .

3. Jayamanne C.S. (1991). Bionomics of the mud crab Scylla serrata. M Phil Thesis, University of Sri Jayewardenepura.

4. Humn J.B. \& Fromm P.O. (1966). In vivo uptake of radio iodide by rainbow trout. Iournal of Water pollution. Control. 38: 1981- 1985. 
5. Hamre K., Lie O., Mage A. \& Julshamn K. (1995). Final report, Norwegian Science Foundation - project number 104617/110. Institute of Nutrition, Directorate of Fisheries, Bergen, Norway.

6. Sreeramulu D. \& Suryanarayana Rao S.V. (1992). Distribution of iodine in marine foods from different regions of India. Indian Journal of Medical, Research 96: $1.68-170$.

7. Sri Lanka Fisheries Year Book (1997). published by National Aquatic Resources Research and Development, Agency. 